shown abnormalities ranging from mild portal inflammation to centrizonal collapse with bridging. The course has been suggestive of a hypersensitivity reaction with a shorter period to development of abnormal liver function after re-exposure to the drug. Ours is the first case with typical pathological features of chronic active hepatitis. The evidence strongly implicated cimetidine. Inadvertent re-exposure to the drug caused rapid recurrence of jaundice and abnormal liver function values, and withdrawal of cimetidine and treatment with prednisone for two months returned these values to normal, although repeat biopsy still showed evidence of chronic active hepatitis. Preexisting chronic active hepatitis exacerbated by cimetidine is unlikely in the absence of other recognised causes of chronic active hepatitis.

This case adds to the slowly accumulating evidence implicating cimetidine as a rare but definite hepatotoxin. The low incidence makes monitoring of liver function values unlikely to be cost effective, but when clinical hepatitis occurs cimetidine must be considered a potential villain.

1 Zuchner H. Cholestatische Hepatose unter Cimetidin. Dtsch Med Wochenschr 1977:102:1788-9.

2 Villeneuve JP, Warner HA. Cimetidine hepatitis. Gastroenterologv 1979;77:143-4

3 Lorenzini I, Jezequel AM, Orlandi F. Cimetidine-induced hepatitis. Electron microscopic observations and clinical pattern of liver injury. Dig Dis Sci 1981;26:275-80.

4 Ruiz Del Arbol L, Moreira V, Morena A, et al. Bridging hepatic cecrosis assuciated with cimetidine. Am $f$ Gastroenterol 1980;74:267-9.

5 Schwartz JT, Gyorkey F, Graham DY. Cimetidine hepatitis. f Clin Gastroenterol 1986;8:681-6.

\section{Cardiotoxic effect with convulsions in terfenadine overdose}

Drs ANTHONy J Davies, V Harindra, A McEwan, and R R GHOSE (Singleton Hospital, Swansea SA2 $8 \mathrm{QA}$ ) write: Terfenadine (Triludan) is a specific, selective, histamine $\mathrm{H}_{1}$ receptor antagonist with few side effects. Four adults have developed prolonged QT intervals with doses of $120-240 \mathrm{mg} /$ day, and ventricular arrhythmias occurred 15 hours after overdose with $3.36 \mathrm{~g}$ in conjunction with $7 \mathrm{~g}$ cephalexin and $1.2 \mathrm{~g}$ ibuprofen. Complications were not observed in 12 other overdoses, six exceeding $1.0 \mathrm{~g}$ (H C Masheter, Merrrell Dow, personal communication). We report a quinidinelike effect on the myocardium with convulsions in a patient with terfenadine toxicity

A healthy 21 year old woman developed two generalised convulsions lasting two minutes 12 and nine hours before admission. There was no incontinence or tongue biting and no residual signs in the central nervous system but an irregular pulse. The patient had been given terfenadine for pruritus seven days earlier. Two tablets daily were prescribed (120 mg) but she took four tablets daily $(240 \mathrm{mg}$ ), except for the day when the convulsions occurred, when she took none. Although 56 tablets had been prescribed only three remained in the packet; the patient claimed she had thrown the rest away.

On admission there were no abnormal physical signs and blood pressure was normal. An electrocardiogram showed prolonged $\mathrm{QT}_{\mathrm{c}}$ intervals, however, with widened notched and inverted $T$ waves and a single premature beat. These changes remained on the second day but reverted to normal. Serial $\mathrm{QT}_{\mathrm{c}}$ intervals were: $0.57 \mathrm{~s}$ on day $\mathrm{l}$, 0.47 s on day $2,0.47$ s on day $3,0.43$ s on day 4 , and $0 \cdot 40 \mathrm{~s}$ on day 5 (normal $0 \cdot 35-0 \cdot 42 \mathrm{~s}$ ). On admission the plasma concentration of terfenadine, measured by radioimmunoassay, was: metabolite $1,504 \mu \mathrm{g} / 1$; unmetabolised terfenadine $43 \mathrm{ug} / \mathrm{l}$. Nine hours later metabolite 1 had fallen to $389 \mu \mathrm{g} / \mathrm{l}$ and unmetabolised terfenadine to $26 \cdot 5 \mu \mathrm{g} / \mathrm{l}$. Liver function values were normal.

The high levels of metabolite 1 and unmetabolised terfenadine on admission, with lowered levels nine hours later, pointed to overdose, although delayed metabolic clearance could not be excluded. These raised concentrations coincided with prolonged $\mathrm{QT}_{\mathrm{c}}$ intervals and widened notched $T$ waves, consistent with a quinidine-like effect. Terfenadine is completely absorbed from the gut, thereafter undergoing extensive first pass metabolism in the liver. Less than $1 \%$ of the oral dose reaches the systemic circulation. The half life is about 17 hours.' Terfenadine is widely distributed throughout the body, but the blood-brain barrier is not breached in animals. Although extrasystoles were noted by the general practitioner, only one was observed in hospital, but convulsing may have resulted from such arrhythmias arising from a cardiotoxic effect. Since 1981, 773 reactions to terfenadine have been reported to the Committee on Safety of Medicines including one case of arrhythmia, one of extrasystole, and one of cardiac arrest. Central nervous system effects included one report of convulsions and two cases of aggravated epilepsy. Cardiotoxic effects may be more common than realised because electrocardiograms are not routinely obtained.

We thank Merrell Dow Research Institute for arranging for measurement of plasma concentration of terfenadine. 1 Okerholm RA, Weiner DL, Hook RH, et al. Bio-availability of
terfenadine in man. Biopharm Drug Dispos 1981;2:185-90.

\section{Pseudopolymyalgia rheumatica during treatment with enalapril}

Professor X LeloËT, Dr N MoORE, and Professor P Deshayes (Department of Rheumatology and Centre Régional de Pharmacovigilance, Hôpital de Boisguillaume, BP 100, 76233 Boisguillaume Cedex, France) write: A 76 year old woman was treated for hypertension from July 1985 with enalapril $20 \mathrm{mg} / \mathrm{day}$. She took no other drugs Three weeks after starting enalapril she started complaining of muscular aches in the right arm. These progressively extended to the other arm shoulders, and then to the pelvic girdle and legs. These aches occurred day and night, causing insomnia, and were accompanied by severe asthenia and morning stiffness lasting three to four hours. Weakness was pronounced and made dressing and getting up from a low stool impossible. She had no dyspnoea, swallowing problem, fever, wasting, or other signs, in particular no headache or eye or skin manifestations.

She was examined in December 1985; her muscles seemed normal and were not painful on palpation, but active mobilisation of the arms and legs caused intense pain in the scapular and pelvic girdles. There was no muscular deficit or ptosis. The neurological examination was normal. The rest of the physical examination was totally unremarkable, and blood pressure was $140 / 85 \mathrm{~mm} \mathrm{Hg}$. Laboratory test results were also all normal, with a normal blood count and no sign of inflammation (erythrocyte sedimentation rate $17 \mathrm{~mm}$ in the first hour, fibrinogen $3 \cdot 1 \mathrm{~g} / \mathrm{l}$ ); creatinine, creatine phosphokinase, and aldolase values were normal; no antinuclear antibodies were found; and latex and Waaler-Rose tests gave negative results. Protein electrophoresis and triiodothyronine and thyroxine concentrations were normal, as were a chest radiograph and electromyograms of all four limbs.

Treatment with indomethacin $75 \mathrm{mg} /$ day by mouth was started on 28 December and partially relieved the daytime muscle pain but not the asthenia or night pain. Having eliminated most known causes of such inflammatory like muscle pain, we suspected enalapril. It was withdrawn on 7 January 1986 and the muscle pain had disappeared completely by 10 January, when indomethacin was also stopped. In January 1988 she was completely symptom free and her hypertension was being treated successfully with reserpine and diuretics.
The typical diagnoses for the symptoms at that age are polymyalgia rheumatica and rheumatoid arthritis affecting the hips and shoulders. Both were excluded, as were other diagnoses such as hypothyroidism and polymyositis. There was no evidence for any other of the usual causes, either viral, bacterial, sarcoid, or metabolic. The paucity of biological signs led us to suspect a drug, suspicion that seems confirmed by the evolution. Despite the absence of rechallenge enalapril seems the likely cause. There was a clear temporal relation with both the onset and the resolution of the symptoms; no other drug was taken; and no other cause was found. The fact that two years later there was no recurrence of symptoms may provide further support, since this would be unusual with any other cause.

Though no case of severe myalgia induced by enalapril has been reported to our knowledge, data from the French adverse drug reaction monitoring system and from the manufacturer indicate that a few other cases of muscular symptoms (myalgia and weakness) exist. The mechanism responsible for these manifestations is unclear. In the event of such incapacitating muscle pain during treatment with enalapril, and once the more common causes have been eliminated, it would seem advisable to test the effects of stopping enalapril before resorting to more invasive or costly tests.

\section{Hair loss in a child associated with naproxen}

Dr Dennis A C BARTER (Paediatric Department, Queen Elizabeth Hospital, King's Lynn PE30 4ET) writes: I report an unfortunate side effect of naproxen (Syntex) when used for the treatment of monarticular arthritis in a 2 year old. She presented at the age of 22 months with a three week history of swelling and limp in the right leg. There was no history of trauma. On examination she appeared well nourished, was afebrile, and cried on taking weight on the right leg. The right knee was swollen and hot and $1.5 \mathrm{~cm}$ greater in circumference than the left. Radiographs of both knees showed no abnormality apart from soft tissue swelling on the right. Although there was no evidence of fracture, the clinical diagnosis was at first thought to be toddler fracture and she was treated with paracetamol. At review, however, monarticular juvenile arthritis was clinically diagnosed. The erythrocyte sedimentation rate at that time was $46 \mathrm{~mm}$ in the first hour. She was stiff in the mornings and limped during the day. Naproxen was started in a dose of $10 \mathrm{mg} / \mathrm{kg}$ (70 mg twice daily). She was given night splints. At review a month later she had made a dramatic improvement, although she still had a morning limp. The swelling was considerably reduced and the redness and temperature change less noticeable. The dose of naproxen was increased to $100 \mathrm{mg}$ twice daily $(13.6 \mathrm{mg} / \mathrm{kg})$. A further month later the mother stated that her hair was falling out and showed photograph of her hair taken in the previous six months, which showed a full head of very curly hair. The knee had improved dramatically: she had no limp or morning stiffness

Our pharmacy found reports of 58 cases of hair loss in adults associated with naproxen and the Committee of Safety of Medicines had reports of 13. None had occurred in children. Dr Barbara Ansell said that she had never seen hair loss at the Medical Research Council's Clinical Research Centre associated with naproxen, though it had not been used in a child as young as this. Naproxen was stopped, and the child's hair regrew dramatically, although without its curls. Fortunately, the monarticular arthritis remained quiescent with no symptoms and no loss of function, although there was still marginal swelling of the right knee.

Naproxen should be used with caution in young children with juvenile chronic arthritis. 